\title{
SPECIATION AND FATE OF COPPER IN SEWAGE TREATMENT WORKS WITH AND WITHOUT TERTIARY TREATMENT: THE EFFECT OF RETURN FLOWS
}

\author{
D. Inna ${ }^{\mathrm{a}}$, J.N. Lester ${ }^{\mathrm{a}}$, M.D. Scrimshaw ${ }^{\mathrm{b}}$ and E. Cartmell ${ }^{\mathrm{a}}$ \\ ${ }^{a}$ Cranfield Water Science Institute, Cranfield University, Cranfield, Bedfordshire, UK, MK43 \\ OAL. \\ ${ }^{\mathrm{b}}$ Institute for the Environment, Brunel University, Uxbridge, Middlesex, UK, UB8 3PH.
}

\begin{abstract}
:
The removal of metals from wastewaters is becoming an important issue, with new environmental quality standards putting increased regulatory pressure on operators of sewage treatment works. The use of additional processes (tertiary treatment) following two-stage biological treatment is frequently seen as a way of improving effluent quality for nutrients and suspended solids, and this study investigates the impact of how back washes from these tertiary processes may impact the removal of copper during primary sedimentation. Seven sites were studied, three conventional two-stage biological treatment, and four with tertiary processes. It was apparent that fluxes of copper in traditional return flows made a significant contribution to the load to the primary treatment tanks, and that $<1 \%$ of this was in the dissolved phase. Where tertiary process were used, back wash liquors were also returned to the primary tanks. These return flows had an impact on copper removal in the primary tanks, probably due to their aerobic nature. Returning such aerobic back wash flows to the main process stream after primary treatment may therefore be worth consideration. The opportunity to treat consolidated liquor and sludge flows in sidestream processes to remove toxic elements, as they are relatively concentrated, low volume flow streams, should also be evaluated.
\end{abstract}




\section{KEYWORDS:}

Metals; Nitrifying Filters; Biological Aerated Flooded Filters; Sludge Liquors; Environmental Quality Standards

\section{Introduction}

Metal removal during wastewater became an early environmental issue because of the contamination of sewage sludges applied to agricultural land [1-4] which continues to this day [5]. Subsequently heavy metals in surface waters came to the fore, this focused attention on removals in unit treatment processes and wastewater treatment as a whole [6-11]. Given the conservative nature of the so-called "heavy metals" their speciation is essentially the partitioning between soluble and solid phases and therefore the factors controlling this became important topics of study [12-20]. The role of specific synthetic organic compounds such as nitrilotriacetic acid in enhancing the solubility of heavy metals including copper and therefore reducing their removal is well established [21,22]. It is well accepted that natural and synthetic substances which constitute components of the soluble chemical oxygen demand $\left(\mathrm{COD}_{\text {sol }}\right)$ can have the same effect as nitrilotriacetic acid. Therefore, $\mathrm{COD}_{\text {sol }}$ can be used as a surrogate measure for this capability [23-28]. Extensive research has been undertaken to understand heavy metal removal during wastewater treatment and in particular in the activated sludge process. The later because only the biological stage of treatment is capable of adsorbing soluble metal ions facilitating their removal by secondary sedimentation [29]. It has been clearly established that minimising effluent $\mathrm{COD}_{\text {sol }}$ will reduce the solubility of many metals thus aiding their removal. Since removal of insoluble bound metal is ultimately dependent on the efficiency of suspended solids removal, the more efficient secondary sedimentation or post biological treatment phase 
separation, the greater the efficiency of metal removal will be [30,31]. Thus in terms of process optimization those measures which produce high quality effluent in terms of $\mathrm{COD}_{\text {sol }}$ and suspended solids (SS) and function consistently achieve optimum metal removal. However, the primary method of minimising heavy metals in sewages and hence in sewage sludges and final effluents has been source control, particularly industrial point sources by trade effluent regulation [32-34]. These measure have led to a reduction of heavy metal discharged to sewer in the United Kingdom (UK) from approximately 12,500 tonnes in 1970 to 1,150 tonnes in 2006 [30].

Given that heavy metals pose environmental and / or human health problems if they enter wastewaters, legal limits for their concentrations in final effluents and surface waters have become increasingly stringent $[33,34]$. Whilst vast reductions have been made in the quantities of toxic elements discharged to sewer the need to remove heavy metals from sewage effluent has resulted in extensive examination of removals in unit treatment processes [29]. However, simultaneously with the need to remove heavy metals, sewage effluents standards have been subject to increasingly stringent regulation for nutrients (nitrate, total nitrogen and phosphate) [35] and organic micropollutants which include numerous groups of synthetic compounds $[36,37]$. It is therefore desirable that removal strategies are applicable to more than a single pollutant or even a single group of pollutants. To achieve these targets much attention has been given to tertiary treatment processes applied to the total flow to the works [38-40] which come with very high economic and environmental costs [41]. The work undertaken here was designed to evaluate whole tertiary treatment of the total flow to the works to establish if it offered any improvement in copper removal in comparison to conventional primary and secondary treatment. 
A novel aspect of the study was to determine the impact of return liquors (frequently containing elevated concentrations of pollutants) on the efficiency of these process configurations. In addition the work aimed to establish if a more elegant and environmental friendly approach could be utilised using side-stream treatment of certain small volume flows in which substances of concern, for example heavy metals, had become concentrated.

\section{Materials and methods}

Seven sewage treatment works (STWs) all utilizing trickling filters for the secondary biological treatment stage were sampled between November 2006 and November 2007. Four of these works had tertiary treatment stages, two utilizing biological aerated flooded filters (BAFFs) sites 4 and 5 and two utilizing nitrifying trickling filters (NTF) followed by sand filtration (sites 6 and 7). However although the NTF at site 6 was operating effectively, the sand filter was not operating and consequently back wash water was not being returned to the head of the works.

Table 1. Site characteristics and operational parameters of the works during the sampling periods.

\begin{tabular}{ccccccc}
\hline Site & $\begin{array}{c}\text { Design } \\
\text { FTFT }^{\mathrm{a}}(1 / \mathrm{s})\end{array}$ & $\begin{array}{c}\text { Actual } \\
\text { FTFT }^{\mathrm{b}}(\%)\end{array}$ & $\begin{array}{c}\text { Returns }^{\mathrm{c}} \\
(\%)\end{array}$ & $\begin{array}{c}\text { Recirculation } \\
(\%)\end{array}$ & $\begin{array}{c}\text { Population } \\
\text { equivalent }\end{array}$ & $\begin{array}{c}\text { Tertiary } \\
\text { treatment }\end{array}$ \\
\hline 1 & 1033 & 44 & 1 & 50 & 156,000 & None \\
2 & 353 & 31 & 5 & 200 & 38,000 & None \\
3 & 216 & 45 & 14 & 26 & 17,330 & None \\
4 & 266 & 39 & 8 & 100 & 40,000 & BAFF $^{\mathrm{e}}$ \\
5 & 736 & 44 & 12 & 23 & 63,000 & $\mathrm{BAFF}^{\mathrm{e}}$ \\
6 & 232 & 49 & 6 & 0 & 20,350 & $\mathrm{NTF}^{\mathrm{d}}$ \\
7 & 440 & 92 & 10 & 0 & 75,000 & $\mathrm{NTF}^{\mathrm{d}}$ \\
\hline
\end{tabular}

\footnotetext{
${ }^{\mathrm{a}}$ Flow to Full Treatment. $\quad{ }^{\mathrm{b}}$ Average FTFT as percentage of design during the week of sampling.

${ }^{\mathrm{c}}$ Returns volume as percentage of FTFT. $\quad{ }^{\mathrm{d}}$ Nitrifying trickling filters (NTF).

${ }^{\mathrm{e}}$ Biological aerated flooded filters (BAFF).
} 
Thus the flow regime at this works was equivalent to a conventional two-stage works such as sites 1-3. The process characteristics of these works are summarized in Table 1 and the works mass balances and process flow diagrams are presented in Figures 1 to 7 . All catchments were predominantly domestic with less than $11 \%$ of the total copper load to the STWs from named traders, with the exception of site 7 where trade input was estimated to be $20 \%$ of total load. All analytical methods, sampling procedures and data processing were as described previously [42].

\section{Results and discussion}

\section{Copper solubility in crude sewage}

The average weekly concentrations of copper in crude sewage are shown in Figure 8 for all sites. It can be seen that with the exception of site 4 the total concentration of copper was between 20 $34 \mu \mathrm{g} 1^{-1}$ with dissolved copper concentrations in the range 2-11 $\mu \mathrm{g} 1^{-1}$. Soluble copper was $20-$ $27 \%$ of the total (Figure 9). Site 4 had a much higher total influent concentration of $117 \mu g 1^{-1}$ of which only $8 \mu \mathrm{g} 1^{-1}$ was soluble. This reflects a single large industrial source of copper, the only site impacted in this manner. Distributions between the solid and soluble phases similar to these values have been reported previously [6,43-49]. Industrial sources may significantly affect total influent concentrations $[11,43,45]$ and can have modest effects on the partitioning between solid and soluble phases. However, the ratio between soluble and solid phases is more frequently affected by other matrix components rather than the copper determinant itself and these components which are often chelating agents $[21,22,50]$, constitute part of the $\mathrm{COD}_{\text {sol }}$ which is often used as a surrogate measure of their concentration. 


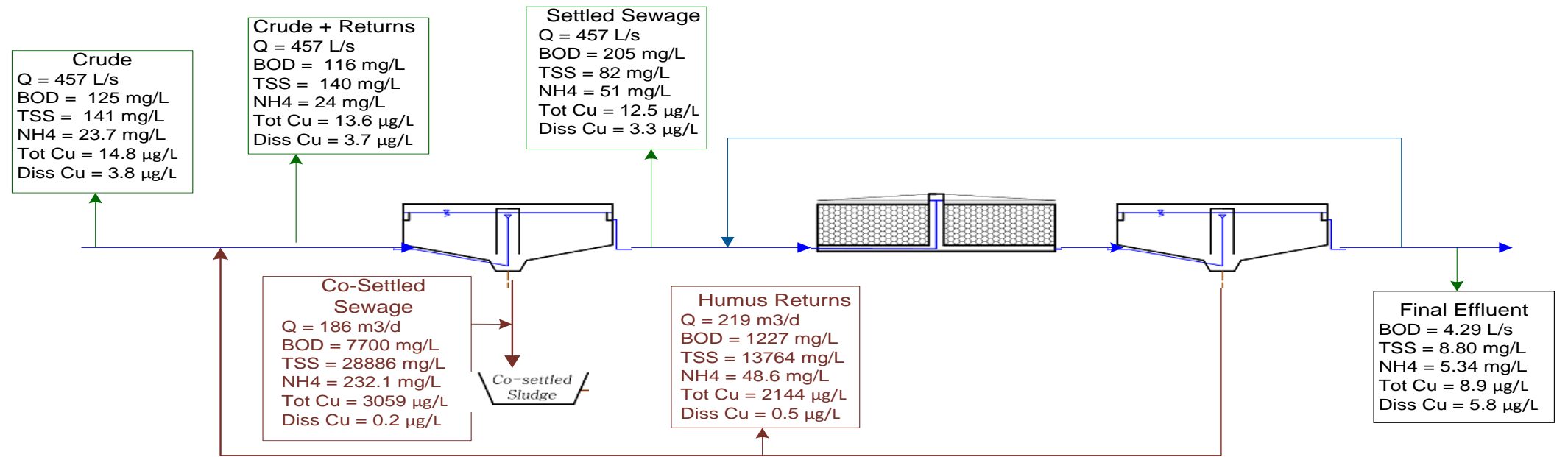

$\mathrm{B}$

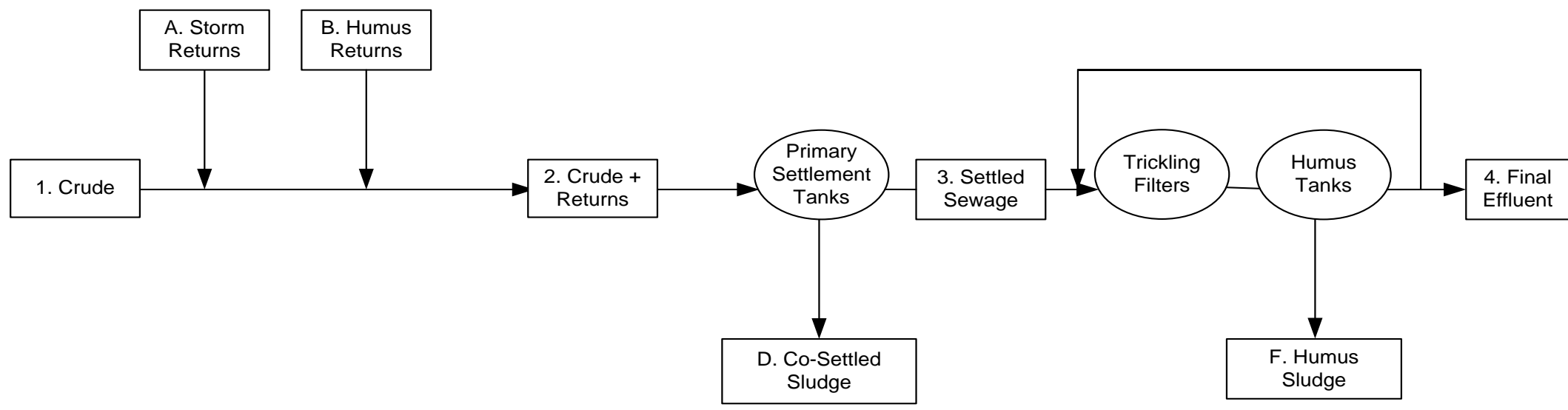

Figure 1. A - the concentrations $\left(\mathrm{mg} \mathrm{L}^{-1}\right.$ or $\left.\mu \mathrm{g} \mathrm{L}^{-1}\right)$ of measured parameters in the wastewater at site 1 . B - the site process flow diagram. Circles represent the unit treatment processes while the numbered or lettered boxes indicate the sampling points. 
A

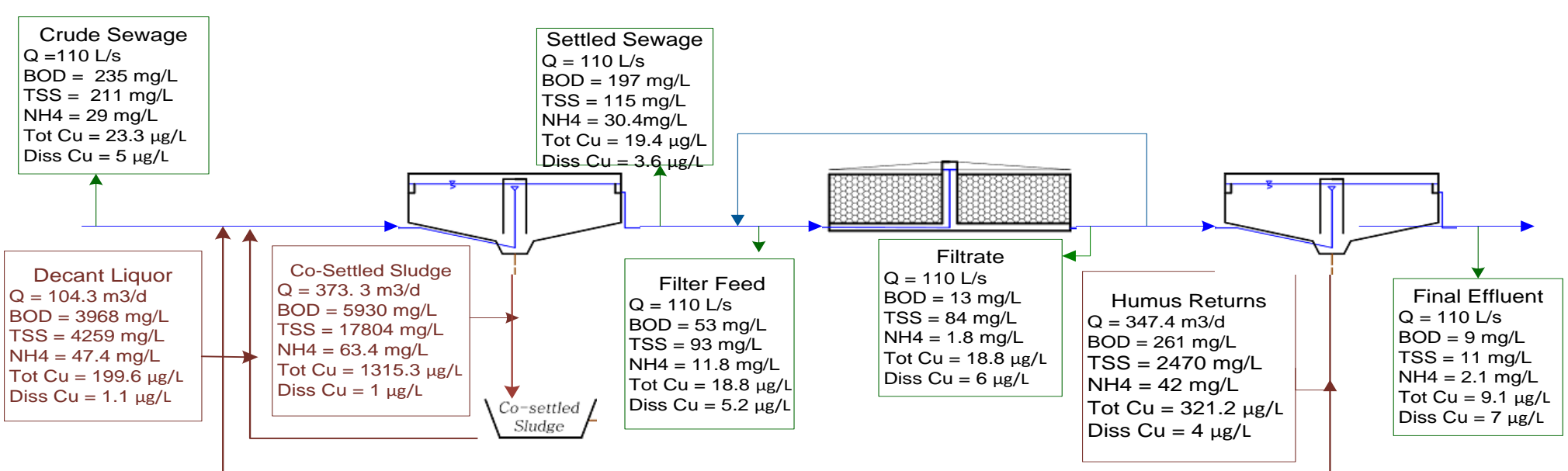

B

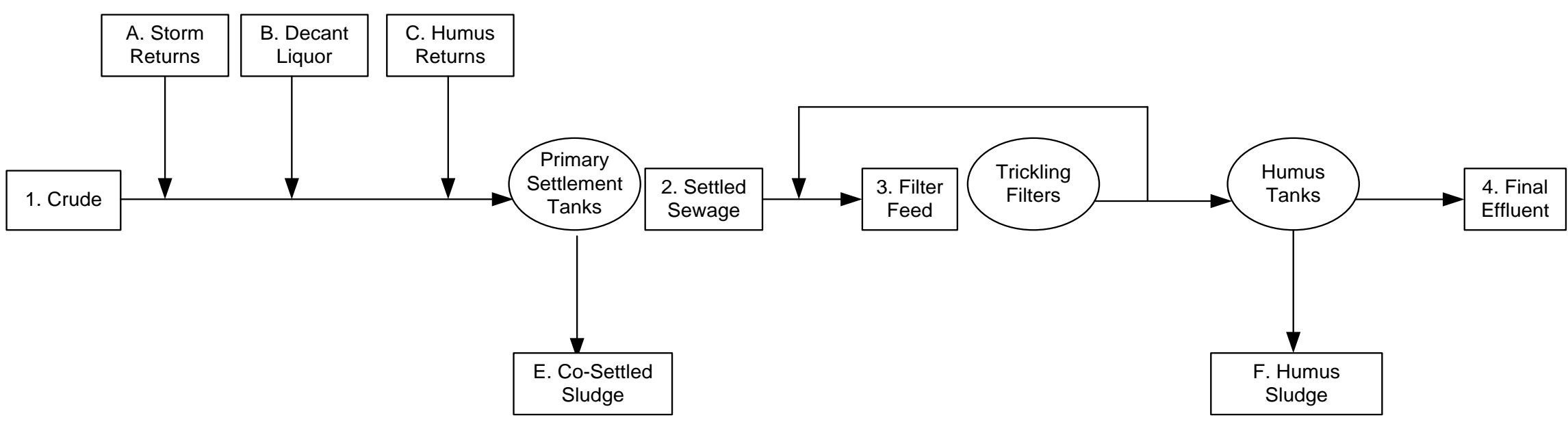

Figure 2. A - the concentrations ( $\mathrm{mg} \mathrm{L}^{-1}$ or $\mu \mathrm{g} \mathrm{L}^{-1}$ ) of measured parameters in the wastewater at site 2. B - the site process flow diagram. Circles represent the unit treatment processes while the numbered or lettered boxes indicate the sampling points. 
A

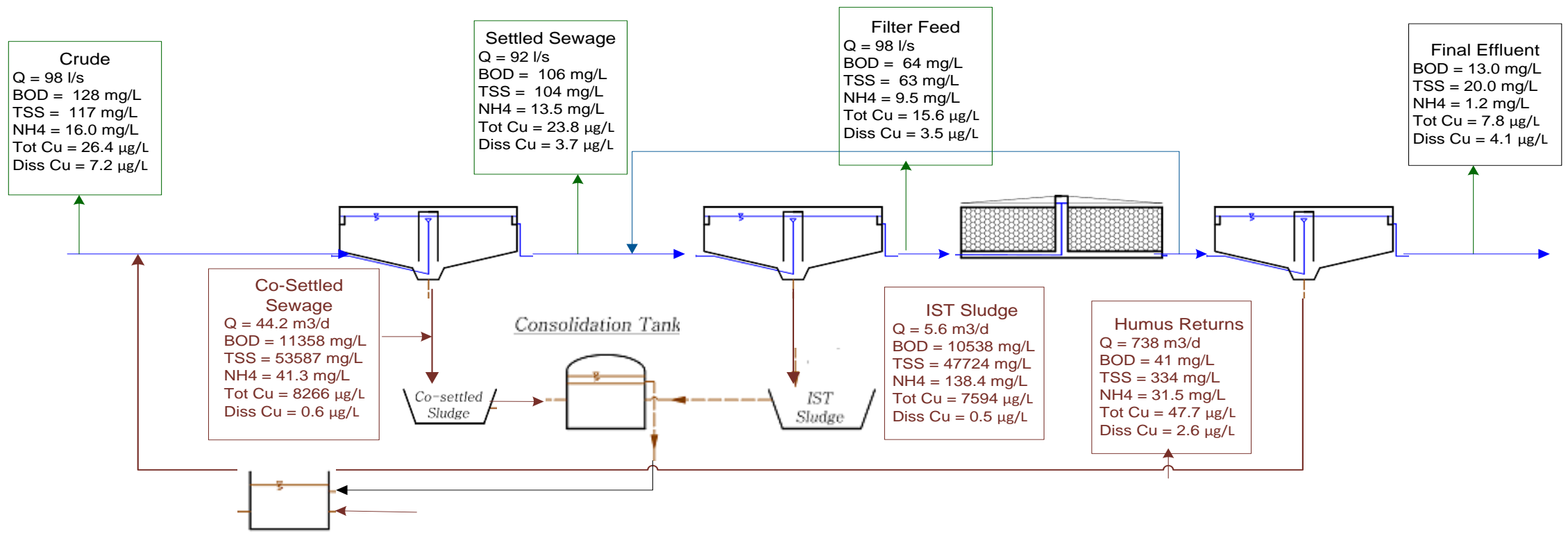

B

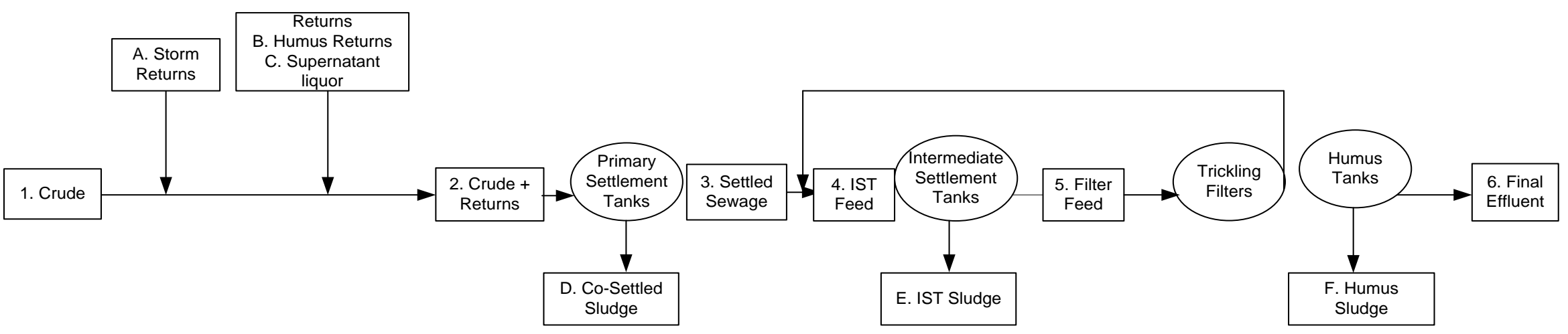

Figure 3. A - the concentrations $\left(\mathrm{mg} \mathrm{L}^{-1}\right.$ or $\mu \mathrm{g} \mathrm{L}^{-1}$ ) of measured parameters in the wastewater at site 3 . B - the site process flow diagram. Circles represent the unit treatment processes while the numbered or lettered boxes indicate the sampling points. 


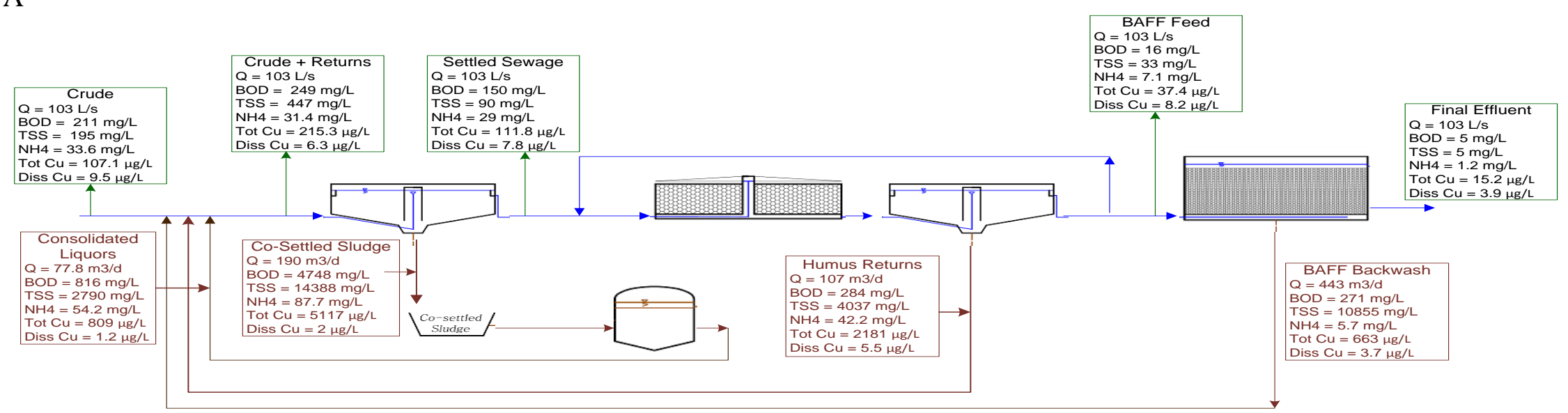

B

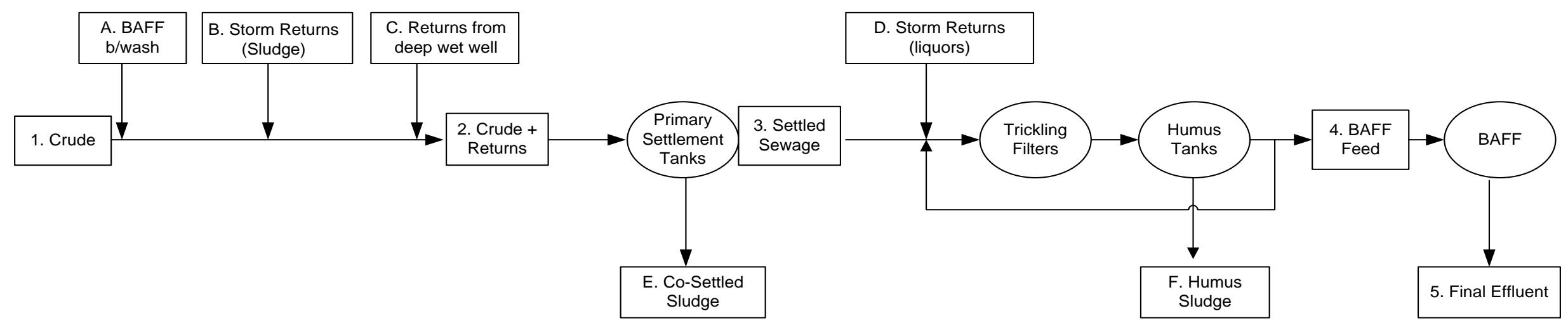

Figure 4. A - the concentrations ( $\mathrm{mg} \mathrm{L}^{-1}$ or $\mu \mathrm{g} \mathrm{L}^{-1}$ ) of measured parameters in the wastewater at site 4 . B - the site process flow diagram. Circles represent the unit treatment processes while the numbered or lettered boxes indicate the sampling points. 
A

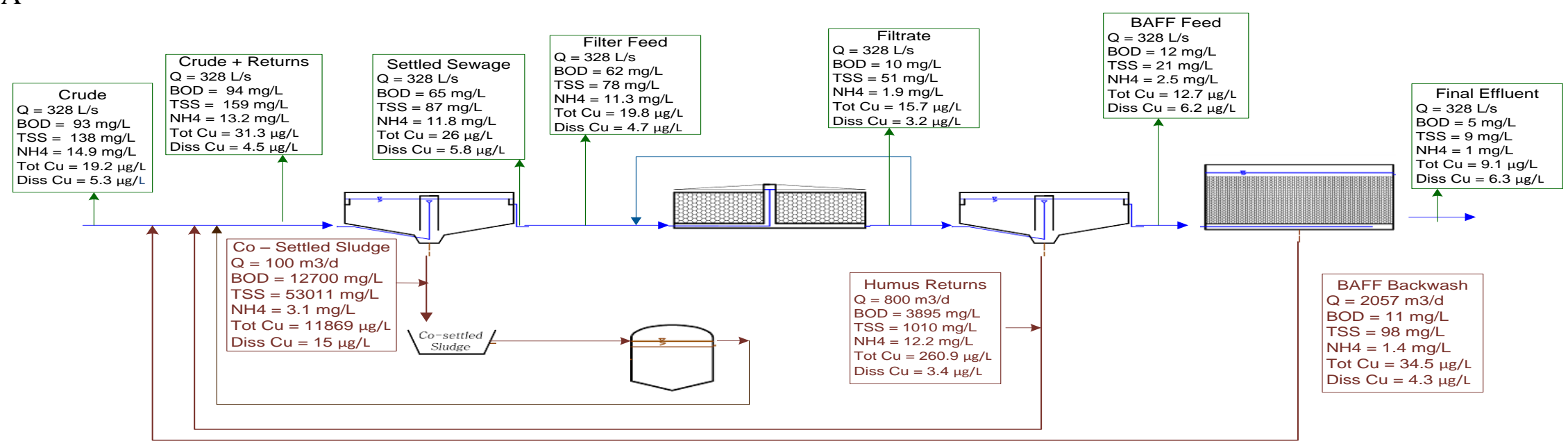

B

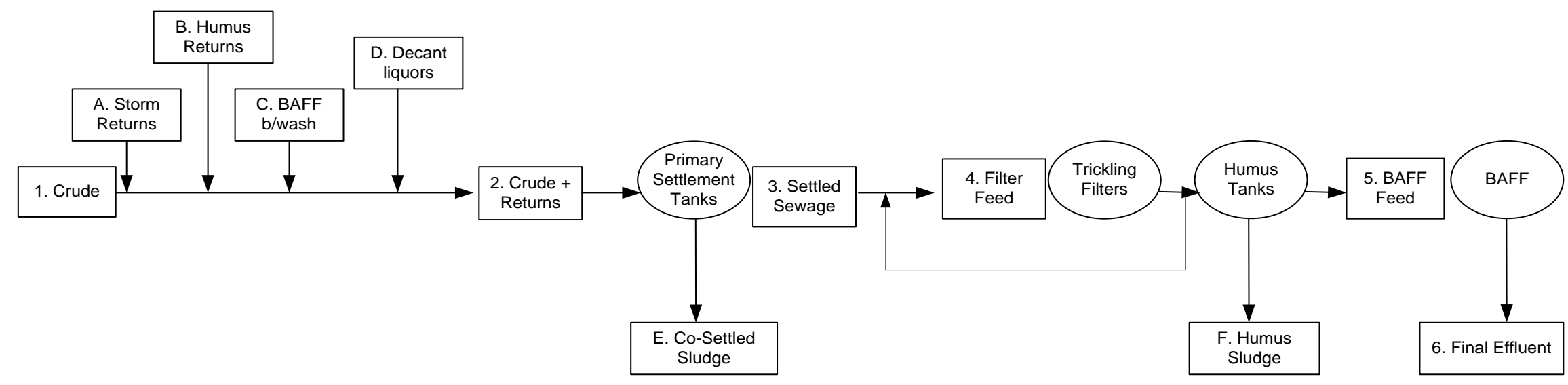

Figure 5. A - the concentrations ( $\mathrm{mg} \mathrm{L}^{-1}$ or $\mu \mathrm{g} \mathrm{L}^{-1}$ ) of measured parameters in the wastewater at site 5. B - the site process flow diagram. Circles represent the unit treatment processes while the numbered or lettered boxes indicate the sampling points. 
A

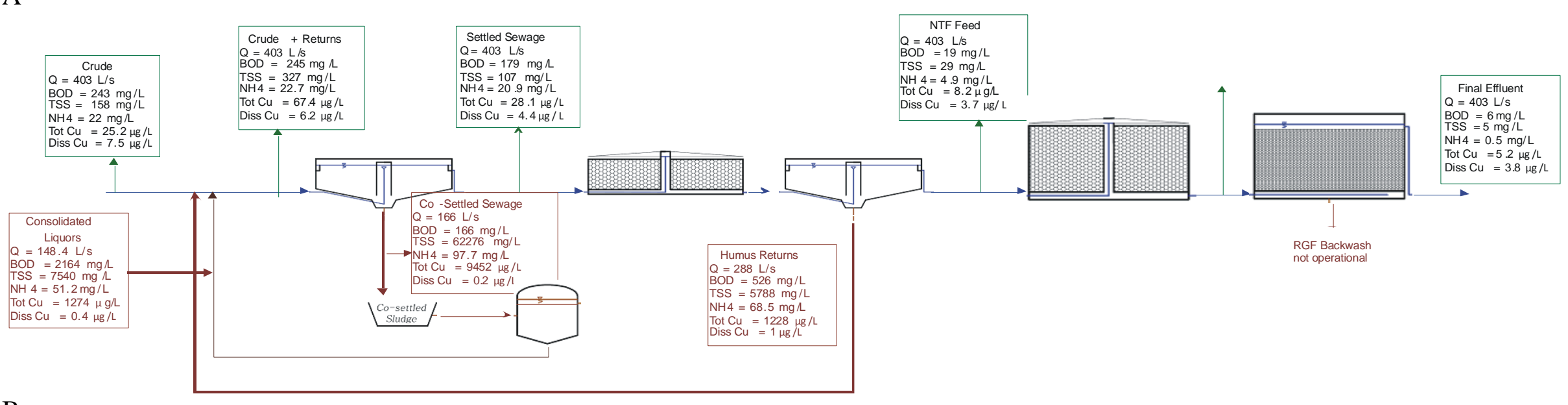

B

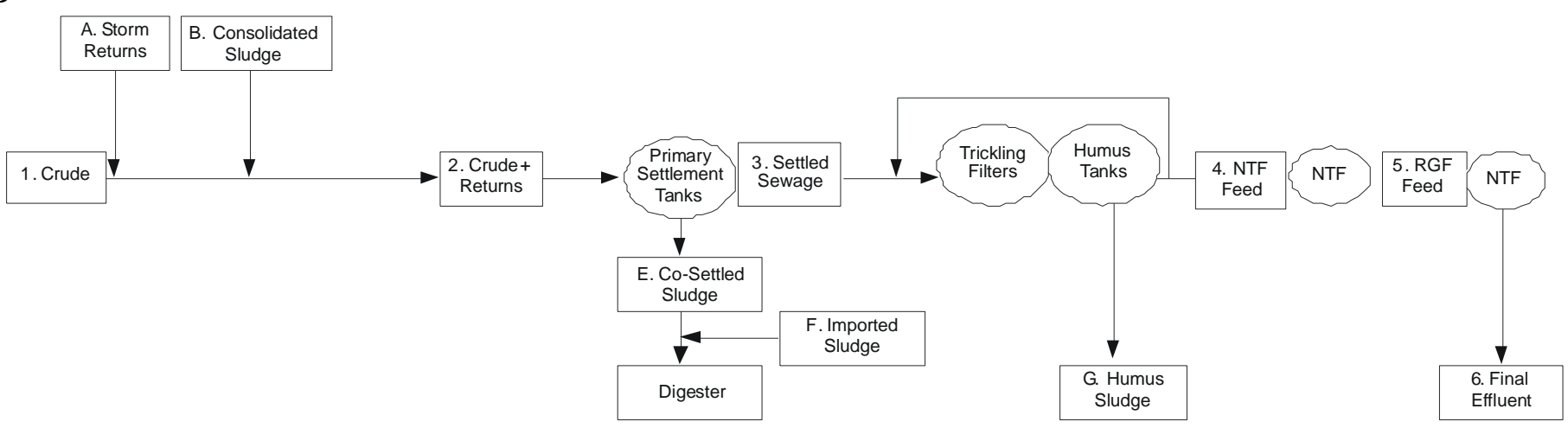

Figure 6. A - the concentrations ( $\mathrm{mg} \mathrm{L}^{-1}$ or $\mu \mathrm{g} \mathrm{L}^{-1}$ ) of measured parameters in the wastewater at site 6 . B - the site process flow diagram. Circles represent the unit treatment processes while the numbered or lettered boxes indicate the sampling points. 


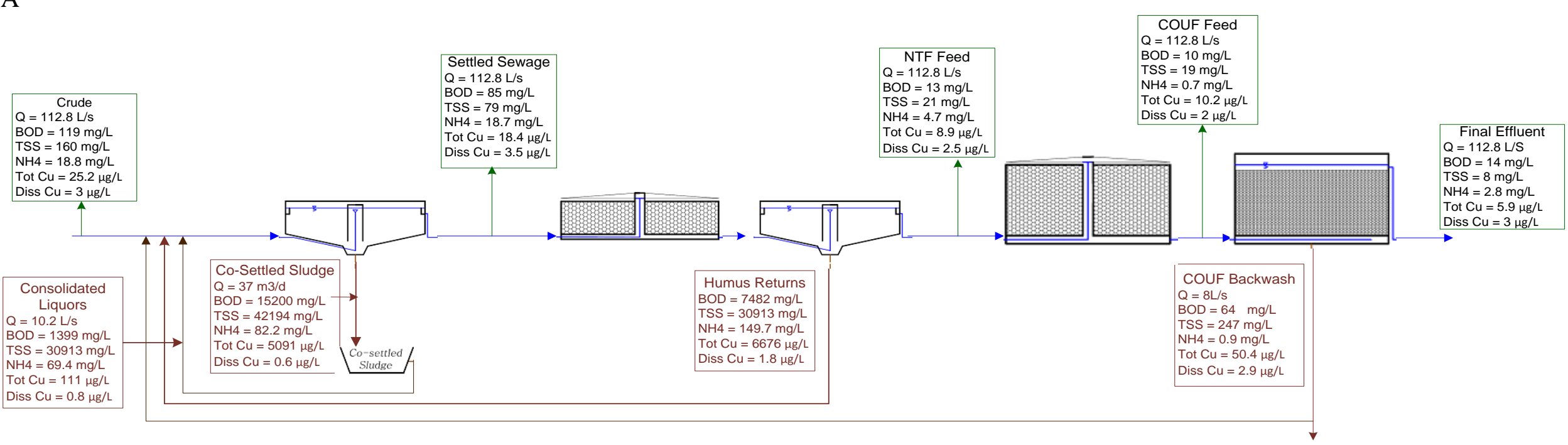

B
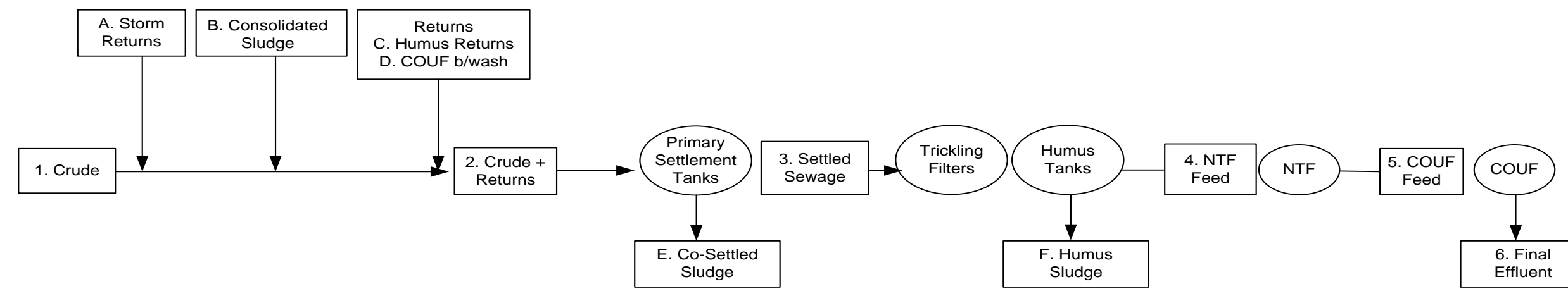

Figure 7. A - the concentrations $\left(\mathrm{mg} \mathrm{L}^{-1}\right.$ or $\mu \mathrm{g} \mathrm{L}^{-1}$ ) of measured parameters in the wastewater at site 7. B - the site process flow diagram. Circles represent the unit treatment processes while the numbered or lettered boxes indicate the sampling points. 


\section{Speciation of copper in return flows}

In this context speciation refers to the partitioning between the solid and soluble phases and those factors which may affect it. Conventional two stage biological sewage treatment results in the production of an effluent and two sludges (primary and secondary, in the case of trickling filters the secondary biological sludge is referred to as humus sludge). Further treatment of the sludges, through settling on-site, results in the production of consolidated liquors which are usually either anoxic or anaerobic in nature. At all sites in this study humus sludge was returned to the primary tanks via the head of works, along with consolidated liquors and the concept of returning such flows to the head of the works is as old as sewage treatment itself. The imposition of more stringent final effluent standards has resulted in the introduction of tertiary treatment processes, these processes almost invariable generate highly aerobic "back wash" returns. The usual means of managing these "back wash" flows is to also return them to the head of the works creating the actual influent to the primary sedimentation process (crude sewage plus returned flows) which has a higher metal load than the crude sewage influent alone (Table 2).

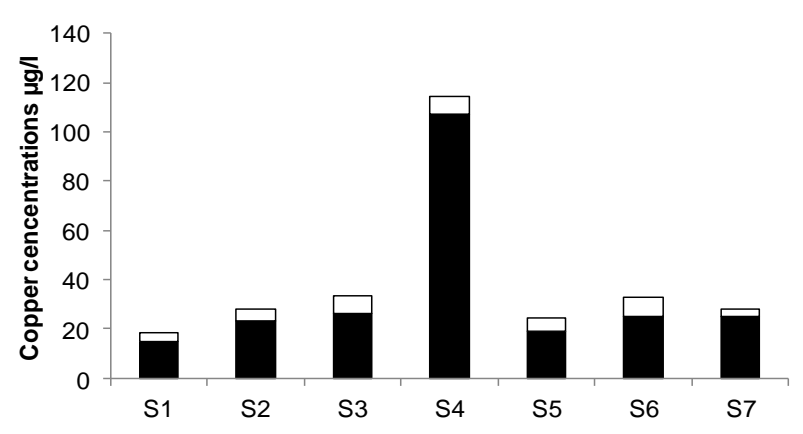

Figure 8. Total ( $\square)$ and dissolved copper ( $\square$ ) concentrations $\left(\mu \mathrm{g} \mathrm{L}^{-1}\right)$ in crude sewage.

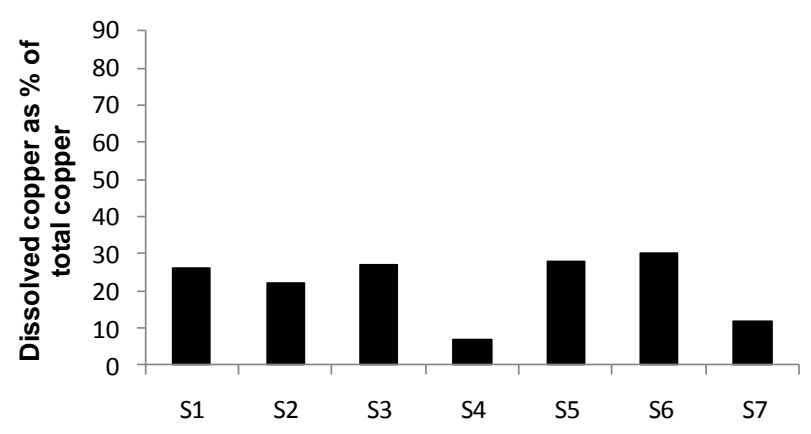

Figure 9. Proportion (\%) of total copper present in the dissolved phase in crude sewage. 
Table 2. Metal flux $\left(10^{-3} \mathrm{~kg} \mathrm{~d}^{-1}\right)$ of total and dissolved copper in works return flows and percent distribution between the dissolved phase and solids.

\begin{tabular}{|c|c|c|c|c|c|c|c|c|c|c|c|c|c|c|c|}
\hline \multirow[t]{2}{*}{ Site } & \multicolumn{5}{|c|}{ HUMUS SLUDGE } & \multicolumn{5}{|c|}{ RETURN LIQUORS } & \multicolumn{5}{|c|}{ BACKWASH RETURNS } \\
\hline & $\begin{array}{c}\text { Flux } \\
\text { dissolved }\end{array}$ & $\begin{array}{l}\text { Flux } \\
\text { solid }\end{array}$ & $\begin{array}{l}\text { Total } \\
\text { flux }\end{array}$ & $\begin{array}{c}\% \\
\text { dissolved }\end{array}$ & $\begin{array}{l}\% \text { on } \\
\text { solids }\end{array}$ & $\begin{array}{c}\text { Flux } \\
\text { dissolved }\end{array}$ & $\begin{array}{l}\text { Flux } \\
\text { solid }\end{array}$ & $\begin{array}{l}\text { Total } \\
\text { flux }\end{array}$ & $\begin{array}{c}\% \\
\text { dissolved }\end{array}$ & $\begin{array}{l}\% \text { on } \\
\text { solids }\end{array}$ & $\begin{array}{c}\text { Flux } \\
\text { dissolved }\end{array}$ & $\begin{array}{l}\text { Flux } \\
\text { solid }\end{array}$ & $\begin{array}{l}\text { Total } \\
\text { flux }\end{array}$ & $\begin{array}{c}\% \\
\text { dissolved }\end{array}$ & $\begin{array}{l}\% \text { on } \\
\text { solids }\end{array}$ \\
\hline 1 & 0.11 & 469 & 470 & $<0.1$ & $>99.9$ & & & & & & & & & & \\
\hline 2 & 1.39 & 110 & 112 & 1.2 & 98.8 & 0.11 & 20.7 & 20.8 & 0.5 & 99.5 & & & & & \\
\hline 3 & 1.92 & 33.3 & 35.2 & 5.5 & 94.5 & & & & & & & & & & \\
\hline 4 & 0.53 & 632 & 633 & 0.1 & 99.9 & 0.07 & 46.9 & 46.9 & 0.1 & 99.9 & 1.64 & 292 & 294 & 0.6 & 99.4 \\
\hline 5 & 2.72 & 206 & 209 & 1.3 & 98.7 & 0.64 & 400 & 401 & 0.2 & 99.8 & 8.85 & 62.1 & 71.0 & 12.5 & 87.5 \\
\hline 6 & 0.29 & 353 & 354 & 0.1 & 99.9 & 0.06 & 189 & 189 & $<0.1$ & $>99.9$ & & & & & \\
\hline 7 & 0.06 & 204 & 204 & $<0.1$ & $>99.9$ & 0.01 & 1.12 & 1.13 & 0.9 & 99.1 & 2.00 & 32.8 & 34.8 & 5.7 & 94.3 \\
\hline Mean & 1.00 & 287 & 288 & 1.2 & 98.8 & 0.2 & 132 & 132 & 0.4 & 99.6 & 5.2 & 126 & 131 & 6.3 & 93.7 \\
\hline
\end{tabular}

It is apparent that the management of every new return flow produced by each additional unit process treatment type has been subject to the established practice of returning them to the head of the works. Whilst the impact of this practice in terms of SS and additional COD may have been considered, little thought to-date has been given to its effects and consequences on metal removal efficiencies and final effluent contaminant concentrations. It is implicit in the "all returns to the head of the works" practice that they behave in a similar manner. When considering the impact of copper loads examination of Table 2 reveals that this is an erroneous conclusion. It is evident that humus returns (secondary biological sludge) contain the largest average mass of copper returning to the head of the works $\left(288 \mathrm{~g} \mathrm{~d}^{-1}\right)$, whilst consolidated sludge liquors and back wash returns constitute less on average $\left(132 \mathrm{~g} \mathrm{~d}^{-1}\right)$. Also evident in Table 2, from examination of the phase distribution, is the limited amount of copper in the dissolved phase of the humus and consolidated liquors (about $1 \%$ and $0.5 \%$ respectively), whilst in the back wash returns up to $8 \%$ of the copper may be in solution. This could reflect both the solids concentrations and/or the anaerobic nature of the matrix in the humus and consolidated liquors. 


\section{Impact of returned liquors on soluble copper removed in primary sedimentation}

In Figure 10 the removal of dissolved copper is plotted against the percentage of the solids contribution from the returns. It is clearly evident that the works fall into two groups. One group is those where solids had no impact (sites 4, 5 and 7). These are the three tertiary treatment works where back wash waters were being returned to the head of the works. The other group comprises the three works with only secondary treatment (sites 1,2 and 3) and site 4 with tertiary treatment but without back wash returns over the sampling period. It is evident there was a clear positive correlation between increased solids and increased removal where back wash returns were not present. However, at the three works with tertiary treatment and operating back wash returns (sites 4, 5 and 7) where the returns were impacted by highly aerobic back wash waters there was no enhancement of removals (Figure 10). With the highly stringent final effluent standards now in place, where only small differences in percentage removal are the difference between pass or fail, the impact of return back wash flows could be important. It appropriate to consider the impact of overall process configuration and not consider metal removal solely within the context of individual unit treatment processes.

Although tertiary processes can be beneficial for solids and ammonia removal the desired benefits for metal removal are not always achieved and could indeed be negative. Based on the observed impact of tertiary back wash returns it could be desirable to separate the aerobic back wash water and reintroduce these returns to settled sewage prior to the trickling filters, thus avoiding their negative impact on soluble copper removal, and potentially other hazardous compounds, during primary sedimentation and where the dissolved oxygen (DO) they contain could potentially be of value for BOD removal. 


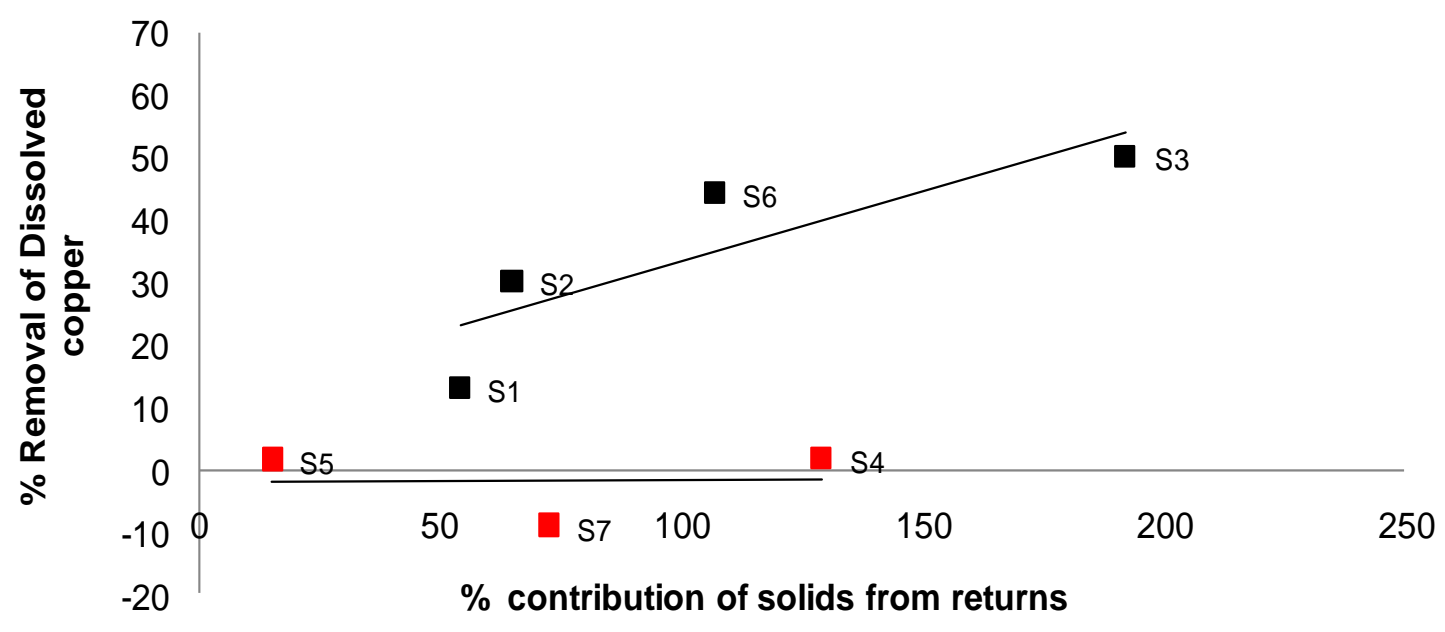

Figure 10. Dissolved copper removal with increasing contribution (\%) of solids to primary tanks from return flows in relation to that in the crude. Sites with operational backwash returns are 4, 5 and 7, where removal of dissolved copper was not observed.

However, the anaerobic/anoxic humus and consolidated sludge liquors returns have been observed to enhance soluble copper removal during primary sedimentation and therefore maintaining their return to the head of the works could remain the optimum approach. Further increases in process efficiency could potentially be achieved by treating the humus and consolidated return flows in a side stream process as these return flows constitute $<1 \%$ of the total flow but contain from $47 \%$ to $65 \%$ of the metal load (Table 3). Consistent with previous studies $[43,46]$, processes such as coagulation, precipitation and absorption could be selected and be economically attractive in terms of both CAPEX and OPEX [41]. It is also apparent that in works with back wash returns, these flows do not contain the majority of the return load (Table 3), but do appear to be detrimental to removal in primary treatment (Figure 10). It may, therefore, be appropriate to consider returning such flows at an alternative point in the treatment process, such as post-primary sedimentation. Such a combined approach, considering the whole treatment process, may thus offer substantial financial as well as environmental benefits 
compared to treating the all return flows with the total flow to treatment, and treating return

flows for the removal of ammonia, to reduce the return load, is an example of how such approaches are being applied with operational benefits [51].

Table 3. The contribution to metal load from return flows at each site and the percent contribution to metal flux in the total return flow from the humus sludge, decant liquors and back wash returns.

\begin{tabular}{|c|c|c|c|c|c|c|c|c|}
\hline Site & & 1 & 2 & 3 & 4 & 5 & 6 & 7 \\
\hline $\begin{array}{l}\text { Contribution from } \\
\text { return flow to } \\
\text { load }(\%)\end{array}$ & & 49 & 48 & 52 & 51 & 59 & 65 & 47 \\
\hline \multirow{3}{*}{$\begin{array}{l}\text { Make up of return } \\
(\%)\end{array}$} & Humus sludge & 100 & 84 & 100 & 65 & 31 & 65 & 85 \\
\hline & Return liquors & & 16 & & 5 & 59 & 35 & \\
\hline & $\begin{array}{l}\text { Back wash } \\
\text { returns }\end{array}$ & & & & 30 & 10 & & 15 \\
\hline
\end{tabular}

\section{Conclusions}

1. Copper is predominantly insoluble in wastewater matrices. Removal is strongly dependent on the removal of suspended solids.

2. Approximately $50 \%$ of the copper in the influent to primary sedimentation is not derived from crude sewage but from the return of various flows to the head of the works.

3. Humus returns and sludge liquors (derived from consolidation and other processes) can enhance soluble copper removal when added to flows prior to primary sedimentation.

4. Back wash waters from BAFFs and RGFs can adversely impact copper removal during primary sedimentation. This is potentially a consequence of their high aerobicity. 
5. Optimisation of metal (and hazardous substance) removal can be achieved through a paradigm shift based on a holistic reassessment of the process flow diagram. This could involve introducing returns at alternative points and/or the adoption of side stream processes.

6. Back wash waters are higher in DO than final effluent and they could possibly be used as the primary source for water used for recirculation over trickling filters. Thus back wash waters returned after primary sedimentation could provide part of the DO requirement for biological treatment.

7. With the returns containing half the metal load in less than $1 \%$ of the total works flow at concentrations up to two orders of magnitude above crude sewage they would be an appropriate target for side stream treatment by precipitation, coagulation or adsorption processes.

\section{REFERENCES:}

1. R.M. Sterritt, and J.N. Lester, The value of sewage sludge to agriculture and effects of the agricultural use of sludge contaminated with toxic elements: a review, Sci. Total Environ. 16 (1980), pp. 55-90.

2. S.R. Smith, A critical review of the bioavailability and impacts of heavy metals in municipal solid waste composts compared to sewage sludge, Environ. Int. 35 (2009), pp. 142-156,

3. M.L. Berrow, and J. Webber, Trace elements in sewage sludges, J. Sci. Food Agric. 23 (1972), pp. 93-100.

4. V.K. Collinge, and A.M. Bruce, Sewage Sludge Disposal: A Strategic Review and Assessment of Research Needs, Water Research Centre, Tech. Rep. 166, Medmenham, UK, (1981).

5. M. Muchuweti, J.W. Birkett, E. Chinyanga, R. Zvauya, J.N. Lester, Heavy metals content of vegetables irrigated with admixtures of wastewaters and sewage: implications for human health. Agr. Eco. Environ. 112 (2006), pp. 41-48.

6. J.N. Lester, R.M. Harrison, and R. Perry, The balance of heavy metals through sewage treatment works. I. lead, cadmium and copper, Sci. Total Environ. 12 (1979), pp. 13-23. 
7. S. Stoveland, M. Astruc, J.N. Lester, and R. Perry, The balance of heavy metals through sewage treatment works. II. chromium, nickel and zinc, Sci. Total Environ. 12 (1979), pp. 25-34.

8. M.J. Brown, and J.N Lester, Metal removal is activated sludge the role of bacterial extracellular polymers, Water Res. 13 (1979), pp. 817-837.

9. J.N. Lester, Significance and behaviour of heavy metals in waste water treatment processes. I. sewage treatment and effluent discharge, Sci. Total Environ. 30 (1983), pp. 144.

10. T. Stones, Fate of metals during sewage treatment, Effluent Water Treat. J. 17 (1977), pp. 653-655.

11. E.F. Barth, M.B. Ettinger, B.V. Salotto, and G.N. McDermott, Summary report on the effects of heavy metals on biological treatment processes, J. Water Pollut. Control Fed. 37 (1965), pp. 86-96.

12. S. Stoveland, and J.N Lester, A study of the factors which influence metal removal in the activated sludge process. Sci. Total Environ. 16 (1980), pp. 37-54.

13. R.M. Sterritt, M.J. Brown, and J.N. Lester, Metal removal by adsorption and precipitation in the activated sludge process. Environ. Pollut. (Series A), 24 (1981), pp. 313-323.

14. T. Rudd, D.L. Lake, I. Mehrota, R.M. Sterritt, P.W.W. Kirk, J.A. Campbell, and J.N. Lester, Characterisation of metal forms in sewage sludge by chemical extraction and progressive acidification, Sci. Total Environ. 74 (1988), pp. 149-175.

15. P.S. Lawson, R.M. Sterritt, and J.N. Lester, Adsorption and complexation mechanisms of heavy metal uptake in activated sludge, J. Chem. Technol. Biotechnol. 34B (1984), pp. 253-262.

16. R.M. Sterritt, and J.N. Lester, The influence of sludge age on heavy metal removal in the activated sludge process, Water Res. 15 (1981), pp. 59-65.

17. V.H. Lewin, and M.J. Rowell, Trace metals in sewage effluent, Effl. Water Treat. J. 13 (1973), pp. 273-277.

18. B.G. Oliver, and E.G. Cosgrove, The efficiency of heavy metal removal by a conventional activated sludge treatment plant, Water Res. 8 (1974), pp. 869-873.

19. H.G. Brown, C.P. Hensley, G.L. McKinney, and J.L. Robinson, Efficiency of heavy metals removal in municipal sewage treatment plants, Environ. Technol. Lett. 5 (1973), pp. 103-107.

20. K.Y. Chen, C.S. Young, and N. Rohatgi, Trace metals in wastewater effluents, J. Water Pollut. Control Fed. 46 (1974), pp. 2663-2675.

21. S. Stoveland, J.N. Lester, and R. Perry, The influence of nitrilotriacetic acid on heavy metal transfer in the activated sludge process. I. at constant loading, Water Res. 13 (1979), pp. 949-965.

22. S. Stoveland, R. Perry, and J.N. Lester, The influence of nitrilotriacetic acid on heavy metal transfer in the activated sludge process. II. at varying and shock loadings, Water Res. 13 (1979), pp. 1043-1054.

23. P.S. Lawson, R.M. Sterritt, and J.N. Lester, Factors affecting the removal of metals during activated sludge wastewater treatment, I. The role of soluble ligands, Arch. Environ. Contam. Toxicol. 13 (1984), pp. 383-390. 
24. P.S. Lawson, R.M. Sterritt, and J.N. Lester, Factors affecting the removal of metals during activated sludge wastewater treatment, II. The role of the mixed liquor biomass. Arch. Environ. Contam. Toxicol. 13 (1984), pp. 391-402.

25. T. Stephenson, and J.N. Lester, Heavy metal behaviour during the activated sludge process. I. Extent of soluble and insoluble metal removal, Sci. Total Environ. 63 (1987), pp. 199-214.

26. T. Stephenson, and J.N. Lester, Heavy metal behaviour during the activated sludge process. II. Insoluble metal removal mechanisms, Sci. Total Environ. 63 (1987), pp. 215230.

27. J. Blok, Disturbance of biological waste water treatment by toxic industrial wastes, Prog. Water Technol. 8 (1976), pp. 179-180

28. F.F. Cantwell, J.S. Nielson, and S.E. Hurdey, Free nickel ion concentration in sewage by an ion exchange column - equilibration method, Anal. Chem. 54 (1982), pp. 1498-1503.

29. A. Santos and S. Judd (2009) The fate of metals in wastewater treated by the activated sludge process and membrane bioreactors: A brief review, J. Environ. Monit. 12 (2010), pp. 110-118.

30. R.S. Crane, P. Barton, E. Cartmell, F. Coulon, P. Hillis, S.J. Judd, A, Santos, T. Stephenson, and J.N. Lester, Fate and behaviour of copper and zinc in secondary biological wastewater treatment processes: I Evaluation of biomass adsorption capacity, Environ. Technol. 31 (2010), pp. 705-723.

31. A. Santos, P. Barton, E. Cartmell, F. Coulon, R.S. Crane, P. Hillis, J.N. Lester, T. Stephenson, S.J. Judd, Fate and behaviour of copper and zinc in secondary biological wastewater treatment processes: II Removal at varying sludge age, Environ. Technol. 31 (2010), pp. 725-743.

32. Commission of the European Communities. Council directive on the use of sewage sludge in agriculture. Off. J. Eur. Community, C264, 3 (1986).

33. European Commission. Directive 2000/60/EC of the European Parliament and of the Council of 23 October 2000 establishing a framework for Community action in the field of water policy. OJ L327, 22.12.2000, 1-72 (2000).

34. European Commission. The Council Directive 2006/11/EC of the European Parliament and of the Council of 15 February 2006 on pollution caused by certain dangerous substances discharged into the aquatic environment of the Community. OJ L64, 04.03.2006, 52-59 (2006).

35. European Commission. The Council Directive 91/271/EEC concerning urban wastewater treatment of 21 May 1991. OJ L135/40, 30.05.91, (1991).

36. UKTAG (UK Technical Advisory Group on the Water Framework Directive). Proposals for environmental quality standards for Annex VIII substances. SR1-2007, final draft, (2007) pp. 77.

37. European Commission. Proposal for a Directive of the European Parliament and of the Council amending Directives 2000/60/EC and 2008/105/EC as regards priority substances in the field of water policy Brussels, 31.1.2012 COM(2011) 876 final 2011/0429 (COD) (2012).

38. M.F. Hamoda, I. Al-Ghusain and N.Z. Al-Mutairi, Sand filtration of wastewater for tertiary treatment and water reuse, Desalination 164 (2004), pp. 203-11.

39. M. Karvelas, A. Katsoyiannis and C. Samara, Occurrence and fate of heavy metals in the wastewater treatment process, Chemosphere 53 (2003), pp. 1201-10. 
40. D. Kobler and M. Boller, Particle removal in different filtration systems for tertiary wastewater treatment: a comparison. Water Sci Technol. 36 (1997), pp. 259-67.

41. O.A.H. Jones, P. Green, N. Voulvoulis, and J.N. Lester, Questioning the excessive use of advanced treatment to remove organic micropollutants from wastewater. Environ. Sci. Technol. 41 (2007), pp. 5085-5089.

42. D. Ziolko, D. Hala, J.N. Lester and M.D. Scrimshaw, The effectiveness of conventional trickling filter treatment plants at reducing concentrations of copper in wastewaters, Sci. Total Environ. 407 (2009), pp. 6235-6241.

43. M.E. Goldstone, P.W.W. Kirk, and J.N. Lester, The behaviour of heavy metals during wastewater treatment I. Cadmium, chromium and copper, Sci. Total Environ. 95 (1990), pp. 223-252.

44. M.E. Goldstone, P.W.W. Kirk, and J.N. Lester, The behaviour of heavy metals during wastewater treatment II Lead, nickel and zinc, Sci. Total Environ. 95 (1990), pp. 253-270.

45. M.E. Goldstone, C. Atkinson, P.W.W. Kirk, and J.N. Lester, The behaviour of heavy metals during wastewater treatment III Mercury and arsenic. Sci. Total Environ. 95 (1990), pp. 271-294.

46. M.E. Goldstone, and J.N. Lester, The balance of heavy metals through sewage treatment works. Technical Note. Sci. Total Environ. 105 (1991), pp. 259-266.

47. R. Buzier, M-H. Tusseau-Vuillemin, C.M. dit Meriadec, O. Rousselot and J-M Mouchel, Trace Metal Speciation and Fluxes within a major French Wastewater Treatment plant: Impact of the Successive Treatment Stages, Chemosphere, 65 (2006), pp. 2419-2426.

48. K.L. Rule, S.D.W. Comber, D. Ross, A. Thornton, C.K. Makropoulos, and R. Rautiu, Survey of Priority Substances Entering Thirty English Wastewater Treatment Works, Water Environ. J., 20 (2006), pp. 177-184.

49. M. Karvelas, A. Katsoyiannis, and C. Samara, Occurrence and Fate of Heavy Metals in the Wastewater Treatment Process, Chemosphere, 53 (2003), pp. 1201-1210.

50. M. Clara, G. Windhofer, P. Weilgony, O. Gans, M. Denner, A. Chovanec and M. Zessner, Identification of relevant micropollutants in Austrian municipal wastewater and their behaviour during wastewater treatment, Chemosphere 87 (2012), pp. 1265-1272.

51. Rogalla, F. Sustainable solutions, Water Wastewater Treat. 54 (2011), pp. 35-36. 
Table Headers

Table 1. Site characteristics and operational parameters of the works during the sampling periods.

Table 2. Metal flux $\left(10^{-3} \mathrm{~kg} \mathrm{~d}^{-1}\right)$ of total and dissolved copper in works return flows and percent distribution between the dissolved phase and solids.

Table 3. The contribution to metal load from return flows at each site and the percent contribution to metal flux in the total return flow from the humus sludge, decant liquors and back wash returns.

Figure Legends

Figure 1. $\mathrm{A}$ - the concentrations $\left(\mathrm{mg} \mathrm{L}^{-1}\right.$ or $\mu \mathrm{g} \mathrm{L}^{-1}$ ) of measured parameters in the wastewater at site 1. B - the site process flow diagram. Circles represent the unit treatment processes while the numbered or lettered boxes indicate the sampling points.

Figure 2. A - the concentrations $\left(\mathrm{mg} \mathrm{L}^{-1}\right.$ or $\mu \mathrm{g} \mathrm{L}^{-1}$ ) of measured parameters in the wastewater at site 2. B - the site process flow diagram. Circles represent the unit treatment processes while the numbered or lettered boxes indicate the sampling points.

Figure 3. A - the concentrations ( $\mathrm{mg} \mathrm{L}^{-1}$ or $\mu \mathrm{g} \mathrm{L}^{-1}$ ) of measured parameters in the wastewater at site 3 . B - the site process flow diagram. Circles represent the unit treatment processes while the numbered or lettered boxes indicate the sampling points.

Figure 4. A - the concentrations $\left(\mathrm{mg} \mathrm{L}^{-1}\right.$ or $\mu \mathrm{g} \mathrm{L}^{-1}$ ) of measured parameters in the wastewater at site 4 . B - the site process flow diagram. Circles represent the unit treatment processes while the numbered or lettered boxes indicate the sampling points.

Figure 5. A - the concentrations ( $\mathrm{mg} \mathrm{L}^{-1}$ or $\mu \mathrm{g} \mathrm{L}^{-1}$ ) of measured parameters in the wastewater at site 5 . B - the site process flow diagram. Circles represent the unit treatment processes while the numbered or lettered boxes indicate the sampling points.

Figure 6. A - the concentrations ( $\mathrm{mg} \mathrm{L}^{-1}$ or $\mu \mathrm{g} \mathrm{L}^{-1}$ ) of measured parameters in the wastewater at site 6 . B - the site process flow diagram. Circles represent the unit treatment processes while the numbered or lettered boxes indicate the sampling points. 
Figure 7. A - the concentrations ( $\mathrm{mg} \mathrm{L}^{-1}$ or $\mu \mathrm{g} \mathrm{L}^{-1}$ ) of measured parameters in the wastewater at site 7 . B - the site process flow diagram. Circles represent the unit treatment processes while the numbered or lettered boxes indicate the sampling points.

Figure 8. Total ( $\square)$ and dissolved copper $(\square)$ concentrations $\left(\mu \mathrm{L} \mathrm{L}^{-1}\right)$ in crude sewage.

Figure 9. Proportion (\%) of total copper present in the dissolved phase in crude sewage.

Figure 10. Dissolved copper removal with increasing contribution (\%) of solids to primary tanks from return flows in relation to that in the crude. Sites with operational backwash returns are 4, 5 and 7, where removal of dissolved copper was not observed. 